\title{
Parâmetros positivos ao controle da administração pública pós-moderna: Uma questão de efetividade constitucional
}

\author{
Kaline Ferreira Davi'
}

\section{Resumo}

O objetivo do presente artigo é demonstrar que a Administração Pública pós-moderna tem um dever prestacional tão relevante num Estado providência como o nosso, que ela deve ser controlada ativamente a realizar ações capazes de promover o bem-estar social através de um instrumental teórico compatível com a dinâmica proposta pelo Direito Administrativo. Para persecução deste objetivo o artigo é estruturado na análise de quatro pontos essenciais: i) a relação entre atividade administrativa e atividade legislativa, com foco na necessidade de constitucionalização do direito administrativo e na concepção, difundida pela doutrina tradicional brasileira, acerca da vinculação da Administração à lei; ii) a superação do paradigma weberiano em razão da necessidade do diálogo entre a técnica e a legitimação política; iii) a questão do alargamento da dimensão da atividade administrativa; e iv) os parâmetros de limite positivo a atuação do Estado. Concluise que as normas constitucionais só serão efetivamente concretizadas, caso haja uma preocupação com os atos de efeito concreto que têm como objetivo direto a mudança da realidade. $\mathrm{O}$ valor e a originalidade do artigo estão relacionados à proposta apresentada de privilegiar um controle estatal voltado para a ação e não para a abstenção.

Palavras-chave: Postmodern Government. Active control. constitutional effectiveness

\footnotetext{
${ }^{1}$ Doutoranda em Direito Público pela Université Bordeaux IV - França. Mestre em Direito Público pela UFBA, Professora de Direito Administrativo na Especialização em Direito do Estado UFBA. kalinedavi@uol.com.br
} 


\section{Introdução}

Causa perplexidade a falta de coincidência entre o discurso constitucionalista - que prega o dirigismo constitucional e a plena efetividade das normas constitucionais - e o discurso da maioria dos administrativistas, que chegam a considerar os atos praticados pelo governo como atos insindicáveis em virtude de forte conotação política.

Pretendemos demonstrar ao longo desse trabalho que a Administração Pública pós-moderna tem um dever prestacional tão relevante num Estado providência como o nosso, que ela deve ser controlada ativamente a realizar ações capazes de promover o bem-estar social, o que se demonstra até mais prioritário do que o controle abstensivo.

No entanto, para que o Estado torne realidade os programas constitucionais, ele deve ser impulsionado ativamente pelos órgãos de controle, que necessitarão de um instrumental teórico compatível com a dinâmica proposta pelo Direito Administrativo, nesse caso já redimensionados pelos valores constitucionais.

\section{Atualização do direito administrativo por intermédio da sua constitucionalização}

Sobre essa proposta de constitucionalização do direito administrativo Paulo Ricardo Schier observa que grande parte dos doutrinadores nacionais, prevalecendo-se de idéias que embasam esse próprio regime jurídicoadministrativo, principalmente a supremacia do interesse público sobre o interesse privado, justificam a vulneração de "direitos fundamentais e de seu regime jurídico-constitucional", ${ }^{2}$ o que demonstra a contramão do direito administrativo

\footnotetext{
${ }^{2}$ SCHIER, Paulo Ricardo. Ensaio sobre a supremacia do interesse público sobre o privado e o regime jurídico dos Direitos Fundamentais. In: SARMENTO, Daniel (Org.). Interesses públicos versus interesses privados: desconstruindo o princípio da supremacia do interesses público. Rio de Janeiro: Lúmen Júris, 2005. p. 114-145.
} 
brasileiro em relação ao processo de neoconstitucionalização ${ }^{3}$. Não existe constitucionalização onde persiste a vulneração de valores primordiais por razões tão pouco democráticas.

No mesmo sentido, Marçal Justen Filho ${ }^{4}$ demonstra que o processo de constitucionalização do direito administrativo ainda está pendente de concretização, porque o instrumental teórico em que se funda esse direito está fora do contexto histórico, social e político do país. Afirma o autor que dotar um país de uma Constituição não é o bastante para se realizar os valores desejados, pois “[...] a transformação concreta da realidade social e sua adequação ao modelo constitucional dependem primordialmente do desenvolvimento de atividades administrativas efetivas".

Adotamos sem restrições o ponto de vista do autor, esclarecendo que a afirmação acima transcrita em nada diminui ou altera a supremacia da Constituição e sua força normativa, ao contrário, permite concretizar os ideais constitucionalistas que têm como elementos caracterizadores formais tanto a supremacia da constituição quanto sua força normativa. A idéia é não permitir que essa supremacia e normatividade constitucionais resumam-se a meros elementos de discurso, o que somente ocorrerá com o auxílio do direito administrativo.

No mesmo sentido afirma Caio Tácito ${ }^{6}$ que o Direito Administrativo e o Direito Constitucional completam-se, pois as Constituições se tornarão inúteis repositórios de conselhos sem o socorro do Direito Administrativo, “[...] que fará do sonho a realidade, da norma programática a efetividade da prestação administrativa, como duas faces que se completam na concretização dos ideais de justiça e igualdade social.”

\footnotetext{
3 "A Constituição passa a ser, assim, não apenas um sistema em si - com sua ordem, unidade e harmonia - mas também um modo de olhar e interpretar todos os demais ramos do Direito. Este fenômeno, identificado por alguns autores como filtragem constitucional, consiste em que toda a ordem jurídica deve ser lida e apreendida sob a lente da Constituição, de modo a realizar os valores nela consagrados. A constitucionalização do direito infraconstitucional não identifica apenas a inclusão na lei maior de normas próprias de outros domínios, mas, sobretudo, a reinterpretação de seus institutos sob uma ótica constitucional." BARROSO, Luís Roberto. Fundamentos teóricos e filosóficos do novo Direito Constitucional brasileiro: pós-modernidade, teoria crítica e pós-positivismo. In: ANJOS FILHO, Robério Nunes dos (Coord.). Estudos de direito constitucional. Salvador: Podium, 2003. p.328- 391.

${ }^{4}$ JUSTEN FILHO, Marçal. Curso de direito administrativo. São Paulo: Saraiva, 2005. p. 36.

${ }^{5}$ JUSTEN FILHO, Marçal. Curso de direito administrativo. São Paulo: Saraiva, 2005. p. 13.

${ }^{6}$ TÁCITO, Caio. A constituição e o direito administrativo. In: CORRÊA, Sérgio Moura (Org.). Temas de direito administrativo. Rio de Janeiro: Forense, 2006. p. 27, 78-90.
} 
Diante dessa premente necessidade de constitucionalização do Direito Administrativo, entra em crise um de seus pilares mais consistentes, que é a vinculação positiva à lei, como se a Administração pudesse ser realmente apenas uma aplicadora mecanicista da regra legal. A erosão da lei formal e o desprestígio do legislador, somados ao surgimento do Estado providência, que criou para a Administração Pública uma série de atribuições novas, culminou com a derrocada do paradigma da estrita vinculação legal.?

Necessário, entretanto, fazermos uma breve análise da doutrina tradicional brasileira e da concepção por ela difundida no meio jurídico acerca da vinculação da Administração à lei.

Para Hely Lopes Meirelles ${ }^{8}$ enquanto na Administração particular é lícito fazer tudo que a lei não proíbe, na Administração pública só é permitido fazer o que a lei autoriza; para Miguel Seabra Fagundes ${ }^{9}$ administrar era aplicar a lei de ofício; para Jean Rivero ${ }^{10}$ a lei era o fundamento e a medida da Administração.

Baseada nessa doutrina clássica foi construída a dogmática do Direito Administrativo brasileiro, que era adequado para um momento histórico, político e sociológico que não mais existe. Construímos um Estado democrático de direito dotado de uma Constituição com força normativa e por isso não podemos admitir que seja imposta uma inversão na sistemática jurídica para privilegiar a norma infraconstitucional em detrimento da Constituição, com absoluta indiferença a sua superioridade.

Para Carmen Lúcia Antunes Rocha ${ }^{11}$, a atividade administrativa é o direito dinamizado. Neste sentido não se pode falar que ela se submete ao Direito, mas sim que ela faz funcionar o Direito posto pela norma, sendo apenas outra etapa desse processo de fazer o Direito, a de concretização. A juridicidade é o liame que

7 BINENBOJM, Gustavo. Uma teoria do direito administrativo. Rio de Janeiro: Renovar, 2006. p. 35.

${ }^{8}$ MEIRELLES, Hely Lopes. Direito administrativo brasileiro. 33. ed. São Paulo: Malheiros, 2007. p. 87.

${ }^{9}$ FAGUNDES, Miguel Seabra. O controle dos atos jurídicos pelo judiciário. 2. ed. Rio de Janeiro: José Konfino, 1950. p. 17.

${ }^{10}$ RIVERO, Jean. Direito administrativo. Coimbra: Almedina, 1981.

${ }^{11}$ ROCHA, Cármen Lúcia Antunes. Princípios constitucionais da administração pública. Belo Horizonte: Del Rey, 2004. p. 83-84. 
identifica o Direito em sua estática (legislação) e em sua dinâmica (administração), conferindo harmonia e unidade à ação estatal.

Podemos concluir, a partir dessa relação direta estabelecida entre a atividade legislativa e a atividade administrativa - dois momentos distintos de elaboração do direito -, que a mesma obediência devida pelo legislador à Constituição da República é devida pelo administrador público, cuja ação tem o mesmo caráter de primariedade que as outras ações estatais, legislação e jurisdição, não se subordinando a nenhuma delas. ${ }^{12}$ Por isso é que Carmen Lúcia Antunes Rocha ${ }^{13}$ justifica a necessidade de submissão da atividade administrativa à lei, já que as duas ostentam qualidade paritária: “[...] para se resgatar a juridicidade que, eventualmente, e por desmando e ruptura em determinado desempenho, se verifique tenha ocorrido.”

Acreditamos, nesse caso, que a lei será parâmetro para a atividade administrativa retomar o curso da legitimidade, o que somente ocorrerá se a lei não tiver divorciada da materialidade da Justiça e da expressão dos valores fundamentais da sociedade, hoje positivados na Constituição. Portanto, é mediante a distinção entre legalidade e legitimidade ${ }^{14}$, amadurecida no século XIX, principalmente a partir do segundo pós-guerra, considerando a legalidade como exercício do poder e a legitimidade como qualidade do poder, que é formada a idéia de juridicidade administrativa, como reunião da forma (legalidade) e da substância (legitimidade). ${ }^{15}$

${ }^{12}$ Em sentido contrário, Geraldo Ataliba defende a superioridade da atividade legislativa: "Essa fenomenologia é universal e tem clara e objetiva explicação: a mais transcendental de todas as funções do Estado é a legislação. Tudo o mais é-lhe subrodinado: todas as demais funções resolvem-se em obedecer à lei, dar cumprimento à lei. Por isso Kelsen valoriza tanto o processo de criação do Direito como critério do estudo científico de suas manifestações." ATALIBA, Geraldo. República e constituição. 2. ed. São Paulo: Malheiros, 2007. p. 68.

${ }^{13}$ ROCHA, Cármen Lúcia Antunes. Princípios constitucionais da administração pública. Belo Horizonte: Del Rey, 2004. p. 84.

${ }^{14}$ Nesse sentido, Diogo de Figueiredo Moreira Neto argumenta: "Nem por outra razão, tenho marcado em meus escritos que entendo a legitimidade como um valor que se agrega à legalidade, pois se esta é a adequação da lei à vontade política formalmente manifestada, a legitimidade é a adequação da manifestação política formal à vontade geral, tal como o entendem grandes pensadores sociais contemporâneos do porte de Carl Schmitt, Niklas Luhmann e Jürgen Habermass." MOREIRA NETO, Diogo de Figueiredo. Mutações do direito público. Rio de Janeiro: Renovar, 2006. p. 52.

${ }^{15}$ ROCHA, Cármen Lúcia Antunes. Princípios constitucionais da administração pública. Belo Horizonte: Del Rey, 2004. p. 104-106. 
Assim, a legalidade administrativa não é rejeitada pelo direito administrativo, mas passa a ocupar uma posição secundária em relação à juridicidade administrativa, que prestigia os princípios e regras constitucionais como parâmetros de aferição da legitimidade das leis.

Depreendemos do que foi exposto que o direito administrativo precisa do constitucionalismo para superar sua defasagem teórica, o que ocorrerá com a adoção do sistema de direitos fundamentais e do sistema democrático. Esses vetores serão responsáveis por imprimir mudanças radicais na relação entre a Administração e os cidadãos - aproximando-os e informando-os - afastando o paradigma weberiano de distanciamento da Administração dos conflitos sociais e políticos como forma de garantir sua autonomia e eficiência. ${ }^{16}$

Defendemos o estabelecimento de um canal de comunicação entre a política e o direito, nos moldes propostos por Maria Paula Dallari Bucci ${ }^{17}$, o que alimentará as alternativas facultadas ao administrador público no exercício da competência discricionária. Esse abandono do isolamento político pela Administração resultará na definição do conteúdo de interesse público de uma forma participativa, em que os titulares do referido interesse serão consultados.

Essa transformação deverá ser instrumentalizada pelo Direito Administrativo constitucionalizado, que passará a reger não somente atos administrativos como expressão da simples execução da lei, mas toda a atividade administrativa, desde a escolha política do caminho a ser seguido, passando por sua execução, até o alcance dos fins. Assim, teremos o mais eficaz instrumento para a concretização dos valores constitucionais, um direito administrativo capaz de resolver os problemas entre

\footnotetext{
16 "Para nós a participação serve justamente para romper com o distanciamento entre sociedade e Administração, aproximando-a dos conflitos sociais e políticos e proporcionando aos administrados uma gestão responsiva, dinâmica, atenta à pluralidade dos interesses sociais, com vistas voltadas à efetivação dos direitos fundamentais, fator essencial para a eficiência das atividades de bem-estar que devem ser conduzidas pela Administração e para a sua legitimidade, tanto em função da adesão racional da sociedade a um conjunto de medidas concretas, políticas ou programas que esta ajudou a formular, decidir e muitas vezes a executar, como em razão da eficiência dessa atuação conjunta.” PEREZ, Marcos Augusto. A participação da sociedade na formulação, decisão e execução das políticas públicas. In: BUCCI, Maria Paula Dallari. Políticas públicas: reflexões sobre o conceito jurídico. São Paulo: Saraiva, 2006. p. 169.

${ }^{17}$ BUCCI, Maria Paula Dallari. Direito administrativo e políticas públicas. 2. tir. São Paulo: Saraiva, 2006. p. 38-40.
} 
Estado e cidadão, autoridade e liberdade, sociedade e indivíduo. Ressaltamos que não se trata de um campo estritamente jurídico, mas sim jurídico-político.

Existe uma lacuna no espaço intra-estatal entre o momento da decisão e o instante da execução. Essa lacuna é um vácuo, no qual as leis e normas não conseguem manter seu poder coativo. Falta o instrumento correto, para nós, a atuação do Direito Administrativo.

\section{Ultrapassando o paradigma weberiano: a politização unida à profissionalização da administração pública}

Concordamos que no século XIX o Estado sofreu um grande avanço na substituição de uma Administração Pública do tipo patrimonialista para um modelo burocrático e Max Weber que foi seu principal idealizador. Este filósofo fixou as bases dessa nova forma de administrar na atuação racional, no estrito cumprimento das leis, num modelo hierárquico rígido, na obediência estrita aos procedimentos e na separação entre a administração especializada e a política. ${ }^{18}$

O tipo de administração patrimonialista erguida com o absolutismo, no qual não havia separação entre o patrimônio público e o privado, originava um contexto satisfatório à proliferação do nepotismo e da corrupção, o que já não era compatível com o cenário que se delineava no século XIX - capitalismo industrial e democracias parlamentares -, época em que a administração pública burocrática foi adotada como solução para os principais problemas do antigo modelo. ${ }^{19}$

Não obstante se mostrar como a alternativa mais viável e compatível com as mudanças políticas e sociais, a Administração Pública burocrática idealizada por Weber não alcançou os resultados esperados em relação à eficiência. Na virada do Estado liberal para o Estado social, verificou-se que a Administração burocrática não garantia rapidez, boa qualidade, nem custo baixo para os serviços prestados ao público, demonstrando-se “[...] pouco ou nada orientada para o atendimento das demandas dos cidadãos".

\footnotetext{
${ }^{18}$ WEBER, Max. Ciência e política: duas vocações. São Paulo: M. Claret, 2006. p. 81-83.

${ }^{19}$ PEREIRA, Luiz C. Bresser. Da administração burocrática à administração gerencial. Revista do Serviço Público, Brasília, ano 47, v. 120, n. 1, p. 95-105, jan./abr. 1996.

${ }^{20}$ PEREIRA, Luiz C. Bresser. Da administração burocrática à administração gerencial. Revista do Serviço Público, Brasília, ano 47, v. 120, n. 1, p. 95-105, jan./abr. 1996.
} 
Nesse momento surgiu um novo modelo de atuação para a Administração Pública, no qual o distanciamento entre ela e os conflitos sociais e políticos era rompido, com a adoção de uma gestão mais adequada à pluralidade dos interesses sociais, visando à satisfação dos direitos fundamentais, tarefa que se constituiu em dever para a Administração de um Estado voltado ao bem-estar social. ${ }^{21}$

Referindo-se a essa dicotomia imposta pela Administração burocrática entre os assuntos políticos e os propriamente administrativos, Maria das Graças Rua ${ }^{22}$ considera essa separação contraditória. Afirma que enquanto a adoção dos meios mais adequados para atingir os fins visados pelo Estado supõe escolha de alternativas previamente estabelecidas pela lei - atividade administrativa instrumental -, a definição primária desses objetivos e dos meios para atingi-los remete ao mundo da política, esfera na qual as próprias alternativas são construídas e as decisões são tomadas em resposta aos interesses, necessidades e demandas freqüentemente conflituosos. $^{23}$

A contradição apontada pela autora reside justamente na suposta racionalidade da atividade administrativa como instrumento de adequação dos meios aos fins. Não há como defender a neutralidade política de uma ação que informa escolhas e decisões que irá executar, gerando adiante outras decisões com base nos resultados anteriores, o que forma um elo indissociável entre a profissionalização, a técnica, a racionalidade e a política.

Diante dessa dependência recíproca entre a burocracia e a política, Paulo Otero $^{24}$ chama atenção para dois movimentos contraditórios no desenvolvimento

${ }^{21}$ PEREZ, Marcos Augusto. A participação da sociedade na formulação, decisão e execução das políticas públicas. In: BUCCI, Maria Paula Dallari (Org.). Políticas públicas: reflexões sobre o conceito jurídico. São Paulo: Saraiva, 2006. p. 164-192.

${ }^{22}$ RUA, Maria das Graças. Desafios da administração pública brasileira: governança, autonomia, neutralidade. Revista do Serviço Público, Brasília, ano 48, n. 3, p. 133-152, set./dez. 1997.

${ }^{23}$ Neste sentido, ao enfatizar a racionalidade enquanto ação instrumental de adequação entre meios e fins, o modelo de administração burocrática como mecanismo de dominação racional-legal implica uma dicotomia entre administração e política que é, ela própria, contraditória. RUA, Maria das Graças. Desafios da administração pública brasileira: governança, autonomia, neutralidade. Revista do Serviço Público, Brasília, ano 48, n. 3, p. 133-152, set./dez. 1997.

${ }^{24}$ OTERO, Paulo. Legalidade e administração pública: o sentido da vinculação Administrativa a Juridicidade. Coimbra: Almedina, 2007. p. 297. 
do Direito Administrativo: a conciliação da legitimidade política das decisões e a crescente exigência de qualificação técnica na satisfação das necessidades coletivas.

Não há mais formulação de processo decisório sem prévio aconselhamento técnico e não há execução das decisões sem esse mesmo aparato especializado. Isto se explica pelo aumento da complexidade técnica dos problemas que são colocados no âmbito do Legislativo e da Administração. São estruturas especializadas que detêm e controlam a informação, prevêem o sucesso das opções entre as diversas alternativas, condicionando em muito as decisões políticas. ${ }^{25}$

Entendemos que esse diálogo inevitável e imprescindível entre a técnica e a legitimação política impede a dissociação entre Administração e Governo. Não há decisão política legítima, quando em desacordo com um parecer técnico que aponta para solução diversa, pois um Estado que acolhe a moralidade e a eficiência administrativas como princípios constitucionais não pode validar uma opção política sem comprometimento com a boa administração. ${ }^{26}$

Vale ressaltar que essa neutralidade política do ideal weberiano tinha como principal objetivo manter a integridade dos valores éticos e morais desejáveis para a Administração Pública, como se isto fosse impossível em relação aos agentes políticos. Tal discriminação não é mais possível no nosso tempo, quando todos devem se pautar de acordo com os padrões éticos vigentes, inexistindo licença para qualquer deles - sejam "políticos" ou "burocratas" - se conduzirem legitimamente de acordo com interesses que não sejam os da coletividade.

Entendemos que os valores democráticos devem prevalecer e imperar sobre o favoritismo, a patronagem, a venalidade e a discriminação em todas as esferas do poder público, sejam elas predominantemente técnicas ou predominantemente políticas.

${ }^{25}$ OTERO, Paulo. Legalidade e administração pública: o sentido da vinculação Administrativa a Juridicidade. Coimbra: Almedina, 2007. p. 296.

${ }^{26}$ Juarez Freitas defende o direito fundamental à boa administração pública como: “[...] direito à administração eficiente e eficaz, proporcional cumpridora de seus deveres, com transparência, motivação, imparcialidade e respeito à moralidade, à participação social e à plena responsabilidade por suas condutas omissivas e comissivas, acarreta o dever de observar, nas relações administrativas, a totalidade dos princípios constitucionais [...]" FREITAS, Juarez. Discricionariedade administrativa e o direito fundamental à boa administração pública. São Paulo: Malheiros, 2007. p. 96. 
A aparente neutralidade da Administração e outorga exclusiva das atribuições políticas ao governo é considerada por Maria Paula Dallari Bucci ${ }^{27}$ como um tipo ideal e não uma descrição que corresponda à realidade das instituições político-administrativas da atualidade. O modelo weberiano é compreensível no contexto da Alemanha pós-Bismarck, onde o Parlamento e o Governo tentavam recuperar atribuições políticas usurpadas pela burocracia, o que demonstra que, para esse modelo, o problema da burocracia era a política.

Assim, analisando o modelo de Administração weberiano, calcado na neutralidade política e na racionalidade, percebemos que esse era o antídoto, à época, para os males vividos com os desmandos da Administração patrimonialista. Ultrapassado esse tempo, não desejamos distanciar os clamores sociais da atividade que tem por fim a realização de seus interesses, nem tampouco separar o aparato técnico da política, para que aquele não se contamine com os valores negativos desta. Queremos uma atividade estatal uniforme, impregnada dos mesmos valores éticos e morais estabelecidos constitucionalmente, o que advirá da regulamentação e controle adequados, tanto em relação à técnica quanto à política.

\section{Alargamento da dimensão da atividade administrativa}

Restou demonstrado que embora não se trate de uma ação desvinculada, a política pressupõe escolha entre alternativas possíveis para alcançar o fim do Estado, cabendo a Administração Pública implementar programas e ações das mais diferentes espécies, o que terá na Constituição a confluência entre o jurídico e o político.

Lênio Streck ${ }^{28}$ considera a Constituição como documento que constitui-aação do Estado, estabelecendo uma nova feição para o direito, que não mais protege o cidadão ante o Estado, mas sim implementa mudanças sociais que deverão ser protagonizadas por esse próprio Estado. Ele acredita que a Constituição pode

\footnotetext{
${ }^{27}$ BUCCI, Maria Paula Dallari. Direito administrativo e políticas públicas. 2. tir. São Paulo: Saraiva, 2006. p. 106-107.

${ }^{28}$ Este e outros juristas, a exemplo de Ferdinand Lassale e Lênio Streck, participaram de uma vídeo-conferência coordenada por COUTINHO, Jacinto Nelson de Miranda. Canotilho e a constituição dirigente. Rio de Janeiro: Renovar, 2003. p. 83.
} 
não se limitar ao que está mais próximo e lançar-se para além da realidade como condição de possibilidade do novo, da emancipação da sociedade, do resgate das promessas da modernidade. Essa é a perspectiva dirigente-compromissária, que vincula a atividade estatal em todas as suas expressões.

Essas considerações nos permitem entender que a idéia de uma Constituição Dirigente não transforma a Constituição em uma norma auto-executória que prescinde da vontade política e administrativa e da atuação humana, únicas capazes de por em prática as disposições normativas. Ao contrário, valendo-nos da lição de Konrad Hesse ${ }^{29}$, verificamos que a força normativa da constituição não se resume apenas à adaptação de uma realidade. A constituição jurídica tem como objetivo converter-se ela mesma em força ativa.

Reforçando esse entendimento, Gilberto Bercovici ${ }^{30}$ afirma que a força normativa da Constituição não depende apenas de seu conteúdo, mas também de sua prática, que não é nada mais do que a expressão da vontade da Constituição, entendida como integração entre a ordem normativa e a conduta humana.

Sem pretender simplificar a complexidade do tema, mas querendo emprestar um cunho didático à questão relativa à política e sua relação com o jurídico, deduzimos, com base na doutrina revisada, que a Constituição é uma norma e tudo o que ela prescreve tem sua mesma natureza, que é normativa, portanto, tudo o que se relaciona à política e foi absorvido pela Constituição passa a ter natureza normativa. Este é um lado da moeda: a natureza jurídica das opções políticas incluídas na Constituição. Contudo as políticas não se iniciam e se finalizam nas normas jurídicas. Admitimos que a política tem suas bases erigidas, num Estado democrático de direito, pelas normas, mas essas são concretizadas mediante processos que contêm atos de diversas categorias e naturezas, unificadas apenas por sua finalidade.

As normas constitucionais estabelecem as premissas materiais, o fundamento e a direção permanente da atuação estatal, mas não substituem as políticas. Segundo

${ }^{29}$ HESSE, Konrad. A força normativa da constituição. Tradução de Gilmar Ferreira Mendes. Porto Alegre: S. A. Fabris, 1991. p. 43.

${ }^{30}$ BERCOVICI, Gilberto. A problemática da Constituição Dirigente: algumas considerações sobre o caso brasileiro. Revista de Informação Legislativa, Brasília, ano 36, n. 142, p. 35-51, abr./jun. 1999. 
Gilberto Bercovici ${ }^{31}$, o programa constitucional não tolhe a discricionariedade do governo, “[...] nem impede a renovação da direção política [...]", mas exige adequação dessa definição de linhas de direção política com os "[...] fins que uma república democrática constitucional fixou em si mesma”.

Ratificando esse posicionamento, Ana Paula de Barcellos ${ }^{32}$ imputa à Administração Pública a tarefa de efetivar os comandos gerais contidos na ordem jurídica, cabendo-lhe implementar ações e programas das mais variadas naturezas, o que a identifica como um conjunto de atividades que considera como políticas públicas.

O Estado que era liberal passou a ser um Estado prestacional e agora se torna um Estado regulador. Todas essas transformações profundas impactam e modificam inteiramente sua forma de atuação e as expectativas geradas em torno dele. $\mathrm{O}$ que se espera de um Estado guardião, protetor não apresenta qualquer identidade com as exigências lançadas sobre um Estado prestador, ordenador e gestor de desenvolvimento social e econômico.

Maria Paula Dallari Bucci ${ }^{33}$ compartilha essa idéia ao comentar que foram atribuídas ao Estado, a partir do século XX, uma série de tarefas complexas que, inevitavelmente, exigem uma comunicação entre a política e o direito, não apenas restrita à Constituição, mas que esteja também presente nos demais atos normativos e nos atos administrativos, capazes de realizar o interesse público, a vontade geral e o bem comum, tudo conforme as formas estabelecidas pelo direito.

Nesse ponto cabe acentuar que a Administração é o Estado em ação, ponto nevrálgico da função de Governo. "É por meio da Administração Pública que o Estado adquire realidade e tem razão de ser." ${ }^{34}$

${ }^{31}$ BERCOVICI, Gilberto. A problemática da Constituição Dirigente: algumas considerações sobre o caso brasileiro. Revista de Informação Legislativa, Brasília, ano 36, n. 142, p. 35-51, abr./jun. 1999.

32 BARCELLOS, Ana Paula de. A eficácia jurídica dos princípios constitucionais. 2. tir. Rio de Janeiro: Renovar, 2002. p. 95.

${ }^{33}$ BUCCI, Maria Paula Dallari. Direito administrativo e políticas públicas. 2. tir. São Paulo: Saraiva, 2006. p. 38-39.

${ }^{34}$ GARCIA, Maria. Prefácio. In: BUCCI, Maria Paula Dallari (Org.). Direito administrativo e políticas públicas. 2. tir. São Paulo: Saraiva, 2006. p. 11-15. 
Reconhece Eros $\mathrm{Grau}^{35}$ que o direito administrativo não pode se ater apenas a instrumentalizar a defesa do indivíduo contra o Estado, mas antes de tudo deve dotar esse novo Estado, que reclama dinamismo, de meios para a concretização dessa Administração concebida como atividade criadora, voltada à realização de determinados fins.

Ciente desta nova perspectiva Marçal Justen Filho ${ }^{36}$ considerou o direito administrativo como o direito disciplinador de atividades necessárias à realização dos direitos fundamentais e a organização e o funcionamento das estruturas estatais e não estatais encarregadas de seu desempenho. ${ }^{37}$

Essa definição alarga em muito as dimensões da atividade administrativa, que passa a ser considerada como realizadora de direitos fundamentais embasados na dignidade da pessoa humana, o que se exterioriza em dois planos distintos: (i) de atuação negativa ou omissiva, o que implica em limitação do poder estatal e não estatal, visando evitar que a concentração de poderes políticos e econômicos produza o sacrifício de liberdades e outros valores fundamentais; (ii) de atuação positiva ou comissiva, o que implica em realização efetiva dos interesses coletivos e com a produção ativa dos valores humanos. ${ }^{38}$

${ }^{35}$ GARCIA, Maria. Prefácio. In: BUCCI, Maria Paula Dallari (Org.). Direito administrativo e políticas públicas. 2. tir. São Paulo: Saraiva, 2006. p. 96.

${ }^{36}$ JUSTEN FILHO, Marçal. Curso de direito administrativo. São Paulo: Saraiva, 2005a. p. 1. A definição proposta pelo autor marca a evolução do direito administrativo em relação às definições tradicionais, que apenas faziam alusão a uma lacônica busca pela finalidade pública, sem estabelecer qualquer ligação entre o direito administrativo e a finalidade precípua do Estado, que é a dignidade da pessoa humana. Para efeito didático, vale transcrever algumas definições tradicionais: Para MEIRELLES, Hely Lopes. Direito administrativo brasileiro. 33. ed. São Paulo: Malheiros, 2007. p. 40: "Conjunto harmônico de princípios jurídicos que regem os órgãos, os agentes e as atividades públicas tendentes a realizar concreta , direta e imediatamente os fins desejados pelo Estado." Para ZANELLA, Maria Sylvia. Discricionariedade administrativa na constituição de 1988. 2. ed. São Paulo: Atlas, 2001. p.52: "Ramo do direito público que tem por objeto os órgãos, agentes e pessoas jurídicas administrativas que integram a Administração Pública, a atividade jurídica não contenciosa que exerce e os bens de que se utiliza para a consecução de seus fins, de natureza pública." Para MELLO, Celso Antônio Bandeira de. Curso de direito administrativo. 20. ed. São Paulo: Malheiros, 2005. p. 35: "É o ramo do direito público que disciplina a função administrativa e os órgãos que a exercem."

${ }^{37}$ JUSTEN FILHO, Marçal. Curso de direito administrativo. São Paulo: Saraiva, 2005.

${ }^{38}$ JUSTEN FILHO, Marçal. Curso de direito administrativo. São Paulo: Saraiva, 2005. p. 3. 
Quanto ao primeiro aspecto - conduta omissiva da Administração - embora ainda seja necessário revisitar vários institutos do Direito Administrativo, capazes de vulnerar essa tarefa de contenção do poder, mostra-se ainda muito mais crítico o segundo aspecto, relacionado com a atividade prestacional do Estado, pois todo o arcabouço do regime jurídico de direito público, reflete uma muralha de contenção - legalidade, separação de poderes -, porém conta com poucos instrumentos aptos a realizar concretamente atividades prestacionais.

Essa dificuldade é apontada por Maria Paula Dallari Bucci ${ }^{39}$, que imputa à teoria liberal ter legado à contemporaneidade um modo de governar que se caracteriza pela falta de comunicação entre as escolhas políticas e as alternativas facultadas ao administrador - discricionariedade. Esse é o modelo burocrático weberiano, no qual a definição do conteúdo de interesse público no nível da Administração é tarefa burocrática e não política.

Acrescenta a autora que a limitação da discricionariedade tem que existir, não há dúvida, mas a forma de limitação existente hoje, representada por um conjunto de barreiras à atuação da Administração Pública em defesa dos direitos individuais, é insuficiente; faltam os parâmetros de limites positivos à ação administrativa, tornando mais transparente as diretrizes informadoras para as escolhas abertas ao Administrador.

Depreendemos do exposto que a atividade administrativa deverá ter estabelecido pelo Direito Administrativo seus limites positivos e negativos, tendo seu âmbito de ação redefinido entre o momento da proposição legal e o da execução da política ${ }^{40}$

Não resta dúvida, diante do que foi visto até aqui, que o Direito Administrativo precisa se contextualizar para poder regulamentar eficazmente essa atividade administrativa criadora, que comunica a técnica e a política, devendo submeter todas as escolhas administrativas ao direito.

${ }^{39}$ BUCCI, Maria Paula Dallari. Direito administrativo e políticas públicas. 2. tir. São Paulo: Saraiva, 2006. p. 39.

40 "Hoje, o desafio da atuação estatal, num Estado como o brasileiro, é exatamente o da coordenação para a execução das políticas, pois o que se tem verificado é que há uma profusão de leis e normas de cunho declaratório (ou meramente retórico) que não encontram eficácia, uma vez que seu poder coativo se perde no espaço intra-estatal entre os momentos da decisão e da execução." BUCCI, Maria Paula Dallari. Direito administrativo e políticas públicas. 2. tir. São Paulo: Saraiva, 2006. p. 40. 


\section{Parâmetros de limite positivo a atuação do estado}

$\mathrm{Na}$ atualidade, o Estado é o principal destinatário das normas constitucionais, mal denominadas de programáticas, exigindo-se dele ora ação, ora omissão. Tratando-se especificamente das ações estatais para a realização desses direitos, o ponto mais crítico do tema são as decisões acerca de dispêndio de recurso público. $^{41}$

A implementação de ações e programas visando efetivar os comandos gerais da ordem jurídica envolve gasto de recursos públicos que são limitados - constatação fática e não jurídica; assim, será preciso priorizar onde gastar o dinheiro público, o que, embora contenha forte caráter político, deve sofrer incidência das normas constitucionais. ${ }^{42}$

Sobre a escassez de recursos públicos e a infinidade de carências humanas e sociais, define-se o problema central das escolhas políticas, que é estabelecer critérios racionais para justificar a promoção desigual de distribuição de ativos sociais, que não deve resultar apenas de uma relação de dominação. ${ }^{43}$ Desse modo, as políticas devem ter caráter redistributivo compatível com a relação entre os benefícios particulares e gerais, tomando por referência um padrão - para nós a Constituição e o devido processo. Caso essa adequação não se efetive, deverá ser acionado o controle judicial.

A promoção, bem como a proteção dos direitos fundamentais exige ações e omissões estatais. Ana Paula de Barcellos ${ }^{44}$ exemplifica, citando a liberdade de expressão que, para ser exercida pelo cidadão, deverá contar com a proteção do poder público que, neste caso, terá caráter omissivo de não cercear ou submeter de alguma forma essa liberdade. Já em relação ao direito à educação formal, prestação de saúde ou condições habitacionais, a situação é bastante diversa, pois estes direitos dependem de ações do Estado.

\footnotetext{
${ }^{41}$ BARCELLOS, Ana Paula de. Neoconstitucionalismo, direitos fundamentais e controle das políticas públicas. Revista de Direito Administrativo, São Paulo, n. 240, p. 83-103, 2005.

42 BARCELLOS, Ana Paula de. Neoconstitucionalismo, direitos fundamentais e controle das políticas públicas. Revista de Direito Administrativo, São Paulo, n. 240, p. 83-103, 2005.

${ }^{43}$ DIAS, Jean Carlos. O controle judicial das políticas públicas. São Paulo: Método, 2007. p. 56.

${ }^{44}$ DIAS, Jean Carlos. O controle judicial das políticas públicas. São Paulo: Método, 2007. p. 9.
} 
Fixando-nos nas obrigações positivas do Estado, concluímos que todos esses imperativos constitucionais que obrigam o Estado a agir vinculam tanto o Legislativo quanto o Judiciário, mas, especialmente, a Administração Pública, a quem cabe efetivar esses comandos gerais, implementando as ações necessárias para obter o resultado esperado: a satisfação desses direitos fundamentais.

Essas implementações e efetivações concretas do comando normativo envolvem gasto de dinheiro público e os recursos financeiros são escassos. Por isso é preciso realizar uma opção, visando priorizar onde serão investidos os recursos públicos. Neste ponto reside a grande questão envolvendo o direito e a discricionariedade política, pois, embora a Constituição indique os fins a serem perseguidos prioritariamente, ainda não está completamente delimitado até onde a discricionariedade como juízo político de conveniência influencia legitimamente nessas deliberações. ${ }^{45}$

Neste momento, entretanto, não estamos tratando da escolha de meios para atingir resultados, mas sim de uma opção bem mais difícil: dentre os resultados a serem buscados pelo Estado, principalmente em matéria de direitos fundamentais, quais devem ser priorizados diante da escassez de recurso. Até onde a Administração poderá escudar sua omissão nessa impossibilidade fática e até onde poderá justificar suas escolhas trágicas - investir em determinada área e abandonar outra igualmente indispensável ou investir mais ou menos recursos nesta ou naquela área. ${ }^{46}$

Em algumas áreas não há opção. Elas são definidas de maneira objetiva pela Constituição Federal de 1988, não cabendo a Administração qualquer espaço para considerações políticas. ${ }^{47}$

${ }^{45}$ DIAS, Jean Carlos. O controle judicial das políticas públicas. São Paulo: Método, 2007. p. 11.

${ }^{46}$ BARCELLOS, Ana Paula de. A eficácia jurídica dos princípios constitucionais. 2. tir. Rio de Janeiro: Renovar, 2002. p. 239.

${ }^{47} \mathrm{O}$ art. 212 da CF/88 determina textualmente percentuais mínimos que a União, os Estados, o Distrito Federal e os Municípios aplicarão na manutenção e no desenvolvimento do ensino; o art. 198, $\$ 2^{\circ}$ dispõe sobre o mínimo de receita arrecadada com determinados tributos que deverão ser aplicadas anualmente pela União, Distrito Federal, Estados e Municípios em ações e serviços públicos de saúde; o art. 195 determina que as receitas obtidas pelas contribuições sociais devam ser investidas no custeio da seguridade social, objetivando assegurar o direito à saúde, à educação e à assistência social, nos termos dos arts. 194 e 195. BARCELLOS, Ana Paula de. A eficácia jurídica dos princípios constitucionais. 2. tir. Rio de Janeiro: Renovar, 2002. p. 18. 
Nos casos em que a Constituição consigna de forma clara e objetiva o quantum se deve investir e em quais setores, não há apenas princípios abstratos regendo a matéria, mas sim regras ${ }^{48}$ de direito que impõem vinculativamente obrigações precisas ao Administrador, a quem não cabe qualquer margem de apreciação subjetiva. São essas as situações mais simples no que tange às atividades prestacionais da Administração.

Na maioria das vezes, contudo, a norma constitucional não tem esse elevado grau de vinculação, norteando as escolhas estatais mediante princípios ${ }^{49}$, o que termina por gerar uma dificuldade na precisão dessas prioridades, dando margem ao exercício de uma suposta discricionariedade por parte do Administrador.

Não obstante essa falsa impressão, mesmo vinculando a atividade estatal mediante princípios, a norma constitucional é imperativa e não deve ser flexibilizada, principalmente em relação aos bens mínimos que devem ser prestados pelo Estado, verdadeiros parâmetros para a exigência de ações e programas, visando sua implementação.

A dificuldade reside em identificar os bens mínimos que não podem deixar de ser ofertados pelo Estado, o que, para Ana Paula de Barcellos ${ }^{50}$, em nada se relaciona com atividade administrativa discricionária, “[...] envolvendo um trabalho hermenêutico que consiste em extrair das disposições constitucionais efeitos específicos, que podem ser descritos como metas concretas a serem atingidas em caráter prioritário pela ação do Poder Público”.

Ingo Wolfgang Sarlet ${ }^{51}$ considera que a existência digna está intimamente relacionada com a prestação de recursos materiais essenciais, devendo ser analisada

\footnotetext{
${ }^{48}$ As regras são as normas que sempre só podem ser cumpridas ou não cumpridas; elas são mandamentos definitivos, exigindo como forma de aplicação a subsunção e não a ponderação. ALEXY, Robert. Direitos fundamentais no estado constitucional democrático. Revista de Direito Administrativo, Rio de Janeiro, v. 217, p. 55-66, jul./set. 1999.

${ }^{49}$ Já os princípios são normas que ordenam que algo seja realizado tão amplamente quanto possível; eles são mandamentos de otimização, podendo ser preenchidos em graus distintos, a depender das possibilidades fáticas ou jurídicas. ALEXY, Robert. Direitos fundamentais no estado constitucional democrático. Revista de Direito Administrativo, Rio de Janeiro, v. 217, p. 55-66, jul./set. 1999.

${ }^{50}$ BARCELLOS, Ana Paula de. Neoconstitucionalismo, direitos fundamentais e controle das políticas públicas. Revista de Direito Administrativo, São Paulo, n. 240, p. 83-103, 2005.

${ }^{51}$ SARLET, Ingo Wolfgang. A eficácia dos direitos fundamentais. Porto Alegre: Livraria do Advogado, 2005. p. 322.
} 
a problemática do salário mínimo, da assistência social, da educação, do direito à previdência social e do direito à saúde.

Ana Paula de Barcellos ${ }^{52}$ identifica como núcleo sindicável da dignidade da pessoa humana quatro elementos retirados da própria Constituição Federal de 1988, sendo três elementos materiais e um elemento instrumental, todos exigíveis judicialmente de forma direta: a educação fundamental, a saúde básica, a assistência no caso de necessidade e o acesso à Justiça.

Consideramos a garantia ao mínimo existencial como um dos fundamentos da República Federativa do Brasil, conforme art. $1^{\circ}$ e $3^{\circ}$ da Constituição Federal de 1988, que assegura existência digna, sociedade justa e erradicação da pobreza, o que de nada valeria se ao homem como sujeito de direito não fosse salvaguardado um núcleo mínimo de direitos que lhe possibilitasse a sobrevivência como pessoa humana.

A Lei Federal 8.742, de 7 de dezembro de 1993, no art. $1^{\circ}$, define a assistência social como política de seguridade social não contributiva, que provê os mínimos sociais, por meio de um conjunto integrado de ações de iniciativa pública e da sociedade, para garantir o atendimento às necessidades básicas. Também o art. 25 da Declaração Universal dos Direitos do Homem, de 1948, prevê que toda pessoa tem direito a um nível de vida suficiente para assegurar sua saúde, seu bemestar e o de sua família, especialmente para a alimentação, o vestuário, a moradia, a assistência médica e os serviços sociais necessários.

A jurisprudência pátria já vem se mostrando sensível à efetivação dos comandos constitucionais como metas prioritárias para a Administração, valendo transcrever decisão do Supremo Tribunal Federal que considerou prioritário o direito à saúde, autorizando inclusive o seqüestro de verbas públicas:

EMENTA: PRECATÓRIO. SEQÜESTRO DE VERBAS PÚBLICAS. CONSTRIÇÃO FUNDADA NO QUADRO DE SAÚDE DO INTERESSADO. AUSÊNCIA DE INDICAÇÃO DE PRETERIÇÃO OU QUEBRA DE ORDEM CRONOLÓGICA. VIOLAÇÃO DA AUTORIDADE DA ADI 1.662. 1. [...] Portanto, ordem de bloqueio de verbas públicas, para pagamento de precatório, fundada no quadro

\footnotetext{
${ }^{52}$ BARCELLOS, Ana Paula de. A eficácia jurídica dos princípios constitucionais. 2. tir. Rio de Janeiro: Renovar, 2002. p. 258.
} 
de saúde do interessado, não viola a autoridade do acórdão prolatado durante o julgamento da ADI 1.662. 4.[.... $]^{53}$

Já por meio de decisão proferida no Agravo Regimental 410715/SP, o STF impôs à Administração a implementação de política pública destinada a promover o acesso à educação infantil, considerando, neste caso, que diante da relevância do direito em questão e da natureza vinculante da regra constitucional prevista no art. 208, IV e 211, $\$ 2^{\circ}$, deveria o judiciário impor ao Executivo a execução das medidas concretas para a efetivação desse direito, sem com isso afetar a separação de poderes. ${ }^{54}$

No mesmo sentido decidiu o STJ em Ação Civil Pública, reduzindo a discricionariedade administrativa a zero, em caso envolvendo implementação de política pública por parte do poder público para a prestação de serviço de saúde gratuito a crianças e adolescentes em hospitais de rede própria. ${ }^{55}$

Desta forma, embora não exista um consenso doutrinário sobre as parcelas que integram o mínimo existencial, não há como negar que esse núcleo existe e que ele transforma a baixa densidade normativa imposta pela natureza das normas principiológicas, em estrita vinculação, não cabendo nenhuma formulação de

${ }^{53}$ BRASIL. Supremo Tribunal Federal. Recurso Extraordinário. Precatório. Seqüestro de verbas públicas. Constrição fundada no quadro de saúde do interessado... RE 3.982/ES. Tribunal Pleno. Relator: Min. Joaquim Barbosa. Brasília, 19 de novembro de 2007. Disponível em: <www.stf.gov.br>. Acesso em: 20 jan. 2008.

${ }^{54}$ Ementa: Recurso extraordinário - Criança de até seis anos de idade - atendimento em creche e em pré-escola - Educação Infantil - Direito assegurado pelo próprio texto constitucional (cf, art. 208, IV) - Compreensão global do direito constitucional à educação - dever jurídico cuja execução se impõe ao poder público, notadamente ao município (CF, art. $211, \S 2^{\circ}$ ) - Recurso Improvido. A educação infantil representa prerrogativa constitucional indisponível, que, deferida às crianças, a estas assegura, para efeito de seu desenvolvimento integral, e como primeira etapa do processo de educação básica, o atendimento em creche e o acesso à pré-escola (CF, art. 208, IV) [...]. BRASIL. Supremo Tribunal Federal. Recurso Extraordinário. AR l410715/SP. Segunda Turma. Relator: Min. Celso de Mello. Brasília, 22 de novembro de 2005. Disponível em: <www.stf.gov.br>. Acesso em: 14 nov. 2007.

${ }^{55}$ Direito constitucional à absoluta prioridade na efetivação do direito à saúde da criança $\mathrm{e}$ do adolescente. norma constitucional reproduzida nos arts. 7 e 11 do estatuto da criança e do adolescente. normas definidoras de direitos não programáticas. exigibilidade em juízo. interesse transindividual atinente às crianças situadas nessa faixa etária. ação civil pública. Cabimento e procedência. BRASIL. Superior Tribunal de Justiça. Recurso especial. REsp 577836/SP. Primeira Turma. Relator: Min. Luiz Fux. Brasília, 21 de outubro de 2004. Disponível em: <www.stj.gov.br>. Acesso em: 14 nov. 2007. 
juízos de oportunidade nos casos que envolvam decisão administrativa acerca da satisfação desse mínimo existencial.

Observemos que ao Judiciário cabe prestar a atividade jurisdicional, que é consectário lógico do direito fundamental de acesso à justiça - considerado inclusive integrante do mínimo existencial -, o que não se verifica apenas pelo direito de pleitear algo judicialmente, mas sim de obter uma decisão que atribua a cada um o que é seu.

Segundo ensinamento de Wilson Alves de Souza ${ }^{56}$, dar a qualquer agente estatal a possibilidade de afastar lesão ou ameaça a direito do controle jurisdicional é claramente negar acesso à justiça.

Não há dúvida de que ao Judiciário competirá a principal tarefa na delimitação desse controle, pois só a ele caberá demonstrar até onde a Administração agiu ou se omitiu sem ferir qualquer disposição constitucional.

Entretanto, ainda existem orientações jurisprudenciais que demonstram a oscilação de entendimento das cortes superiores, verifique-se decisão do STJ:

EMENTA: RECURSO ORDINÁRIO. MANDADO DE SEGURANÇA. LICENÇA DE OBRAS DE MODIFICAÇÃO E REFORMA NO MORRO DA URCA E NO MORRO DO PÃO DE AÇÚCAR E LICENÇA PARA A INSTALAÇÃO DE ELEVADORES DESTINADOS A DEFICIENTES FÍSICOS. ALEGADA OMISSÃO DO PREFEITO DO MUNICÍPIO DO RIO DE JANEIRO. NÃO-EVIDENCIADA A PRESENÇA DE SUPOSTO DIREITO LÍQÜIDO E CERTO. DISCRICIONARIEDADE DA MUNICIPALIDADE. NÃO-CABIMENTO DE INTERFERÊNCIA DO PODER JUDICIÁRIO NA ESPÉCIE.

[...] Ainda que assim não fosse, com fulcro no princípio da discricionariedade administrativa e na supremacia do interesse público, a Municipalidade tem liberdade para decidir pela conveniência ou não da execução da obra. Como ensina Hely Lopes Meirelles, "só o administrador, em contato com a realidade, está em condições de bem apreciar os motivos ocorrentes de oportunidade e

\footnotetext{
${ }^{56}$ SOUZA, Wilson Alves de. Acesso à justiça e responsabilidade civil do estado por sua denegação: estudo comparativo entre o direito brasileiro e o direito português. 2006. $423 \mathrm{f}$. Tese (Pós-Doutoramento em Direito Público)- Universidade de Coimbra, Coimbra, 2006. f. 165.
} 
conveniência na prática de certos atos [...]. Só os órgãos executivos é que estão, em muitos casos, em condições de sentir e decidir administrativamente o que convém e o que não convém ao interesse coletivo". Recurso ordinário improvido. ${ }^{57}$

A Constituição Federal estabelece em diversos dispositivos a obrigação de a Administração Pública garantir os direitos das pessoas com deficiência ${ }^{58}$, o que não foi levado em conta pelo Tribunal Superior, apegado a uma discricionariedade que concederia à municipalidade uma "[...] liberdade para decidir pela conveniência ou não da execução da obra" dos elevadores para acesso aos portadores de deficiência física.

Decisão como esta retira boa parte do potencial dirigente da Constituição Federal. Os instrumentos utilizados pelos Tribunais, quando querem retroagir às velhas concepções dogmatizadas, são extraídos do deficitário direito administrativo e de suas teorias arcaicas, como é o caso do tratamento dispensado à competência discricionária.

Isto justifica a preocupação em superar o déficit teórico do direito administrativo, para que ele possa ser um instrumento eficaz na efetivação das normas constitucionais.

\section{Conclusão}

Discutimos ao longo deste trabalho o estabelecimento de parâmetros positivos para o controle da atuação de uma Administração Pública não só burocrática e limitadora, mas também realizadora, traçando metas, planejando, programando e realizando políticas públicas implementadoras de direitos fundamentais.

${ }^{57}$ BRASIL. Superior Tribunal de Justiça. Recurso Ordinário em Mandado de Segurança. RMS 19535/RJ 2005/0017692-9. Segunda Turma. Relator: Min. Franciulli Netto. Brasília, 01 de setembro de 2005. Disponível em: <www.stj.gov.br>. Acesso em: 11 nov. 2007.

${ }^{58}$ Constituição Federal de 1988, Art. 23: "É competência comum da União, dos Estados, do Distrito Federal e dos Municípios: [...] II - cuidar da saúde e assistência pública, da proteção e garantia das pessoas portadoras de deficiência; [...]" Art. 244. "A lei disporá sobre a adaptação dos logradouros, dos edifícios de uso público e dos veículos de transporte coletivo atualmente existentes a fim de garantir acesso adequado às pessoas portadoras de deficiência, conforme o disposto no art. $227, \S 22^{\circ}$." 
A lacuna hoje ainda existente no espaço intra-estatal entre o momento da decisão e o instante da execução será suprida quando o direito administrativo assumir sua importante tarefa, que é dotar todos os implicados nessa concretização de direitos fundamentais - povo, estado, particulares - de instrumentos teóricos próprios e alinhados com a realidade sociopolítica.

Sobre a Constituição dirigente, acreditamos que ela pode resgatar as promessas da modernidade, isto, entretanto, não prescinde da vontade política e administrativa e da atuação humana, únicas capazes de por em prática as disposições normativas.

Apresenta-se como problema central das escolhas políticas estabelecer critérios racionais para justificar a promoção desigual de distribuição de ativos sociais, que não devem resultar apenas de uma relação de dominação, mas devem respeitar um padrão que será a Constituição e o devido processo. Caso essa adequação não se efetive, deverá ser acionado o controle judicial, legislativo ou popular.

O direito administrativo, ao regular a concretização do político, faz valer o parágrafo único do art. $3^{\circ} \mathrm{da} \mathrm{CF} / 88$, ao afirmar que o poder político é do povo e, implicitamente, que ele só se legitima à medida que seja exercido em seu nome e a serviço de seus interesses. Essa máxima republicana somente será verdadeira quando não existir nenhuma atuação estatal que fuja aos mecanismos de controle.

\section{Positive parameters of a postmodern administration control: A matter of constitutional effectiveness}

\section{Abstract}

The aim of this paper is to demonstrate that the postmodern Administration service has a duty so important in the welfare state like ours, that it must be actively controlled to perform actions that can promote social welfare through a theoretical tool compatible with the dynamics proposed by Administrative Law. In pursuing this objective the paper is structured in the analysis of four key points: i) the relation between administrative activity and legislative activity, focusing on the need for a constitutionalization of administrative law and the conception diffused by the traditional Brazilian doctrine, on the binding of the Administration the law, ii) to overcome the Weberian paradigm having in mind the need for dialogue between the technical and 
political legitimacy; iii) the question of augmentation of administrative activity, and iv) limiting parameters of positive state action. This article concludes that the constitutional norms will only be effectively implemented if there is a concern about the concrete actions that has as an objective the direct change of reality. The value and originality of the article are due to the proposal of giving priority to state control aimed at positive action and not to abstention of action.

Keywords: Postmodern Government. Active control. Constitutional effectiveness

\section{Referências}

ALEXY, Robert. Direitos fundamentais no estado constitucional democrático. Revista de Direito Administrativo, Rio de Janeiro, v. 217, p. 55-66, jul./set. 1999.

ATALIBA, Geraldo. República e constituição. 2. ed. São Paulo: Malheiros, 2007.

BAPTISTA, Patrícia. Transformações do direito administrativo. Rio de Janeiro: Renovar, 2003.

BARCELLOS, Ana Paula de. A eficácia jurídica dos princípios constitucionais. 2. tir. Rio de Janeiro: Renovar, 2002.

BARCELLOS, Ana Paula de. Neoconstitucionalismo, direitos fundamentais e controle das políticas públicas. Revista de Direito Administrativo, São Paulo, n. 240, p. 83-103, 2005.

BARROSO, Luís Roberto. Fundamentos teóricos e filosóficos do novo Direito Constitucional brasileiro: pós-modernidade, teoria crítica e pós-positivismo. In: ANJOS FILHO, Robério Nunes dos (Coord.). Estudos de direito constitucional. Salvador: Podium, 2003.

BARROSO, Luís Roberto. Interpretação e aplicação da Constituição. 5. ed. São Paulo: Saraiva, 2003.

BERCOVICI, Gilberto. A problemática da Constituição Dirigente: algumas considerações sobre o caso brasileiro. Revista de Informação Legislativa, Brasília, ano 36, n. 142, p. 35-51, abr./jun. 1999.

BERCOVICI, Gilberto. Planejamento e políticas públicas. In: BUCCI, Maria Paula Dallari (Org.). Políticas públicas: reflexões sobre o conceito jurídico. São Paulo: Saraiva, 2006. 
BINENBOJM, Gustavo. Uma teoria do direito administrativo. Rio de Janeiro: Renovar, 2006.

BRASIL. Superior Tribunal de Justiça. Recurso especial. REsp 577836/SP. Primeira Turma. Relator: Min. Luiz Fux. Brasília, 21 de outubro de 2004. Disponível em: <www.stj. gov.br>. Acesso em: 14 nov. 2007.

BRASIL. Superior Tribunal de Justiça. Recurso Ordinário em Mandado de Segurança. RMS 19535/RJ 2005/0017692-9. Segunda Turma. Relator: Min. Franciulli Netto. Brasília, 01 de setembro de 2005. Disponível em: <www.stj.gov.br>. Acesso em: 11 nov. 2007.

BRASIL. Supremo Tribunal Federal. Argüição de Descumprimento de Preceito Fundamental. Argüição de descumprimento de preceito fundamental. a questão da legitimidade constitucional do controle e da intervenção do poder judiciário em tema... ADPF 45/DF. Relator: Min. Celso de Mello. Brasília, 29 de abril de 2004. Disponível em: $\quad<$ http://www.stf.jus.br/portal/jurisprudencia/listarJurisprudencia.asp?s1=45. NUME.\&base=baseMonocraticas $>$. Acesso em: 20 ago. 2007.

BRASIL. Supremo Tribunal Federal. Recurso Extraordinário. AR 1410715/SP. Segunda Turma. Relator: Min. Celso de Mello. Brasília, 22 de novembro de 2005. Disponível em: <www.stf.gov.br>. Acesso em: 14 nov. 2007.

BRASIL. Supremo Tribunal Federal. Recurso Extraordinário. Precatório. Seqüestro de verbas públicas. Constrição fundada no quadro de saúde do interessado... RE 3.982/ ES. Tribunal Pleno. Relator: Min. Joaquim Barbosa. Brasília, 19 de novembro de 2007. Disponível em: <www.stf.gov.br>. Acesso em: 20 jan. 2008.

BUCCI, Maria Paula Dallari. Direito administrativo e políticas públicas. 2. tir. São Paulo: Saraiva, 2006.

BUCCI, Maria Paula Dallari. Políticas públicas: reflexões sobre o conceito jurídico. São Paulo: Saraiva, 2006.

CASTRO, Celso Braga de. Desvio de conduta na administração pública. 1995. 135 f. Dissertação (Mestrado em Direito)- Faculdade de Direito, Universidade Federal da Bahia, Salvador, 1995.

CLÈVE, Clèmerson Merlin. Temas de direito constitucional. São Paulo: Acadêmica, 1993.

COMPARATO, Fábio Konder. Ensaio sobre juízo de constitucionalidade das políticas públicas. In: MELLO, Celso Antônio Bandeira de (Org.). Estudos em homenagem a Geraldo de Ataliba. São Paulo: Malheiros, 1997. p. 49-65. v. 2. 
COMPARATO, Fábio Konder. Planejar o desenvolvimento: a perspectiva institucional. In: BERNARDO, Antonio C. et al (Org.). Brasil, o desenvolvimento ameaçado: perspectivas e soluções. São Paulo: UNESP, 1989.

COUTINHO, Jacinto Nelson de Miranda. Canotilho e a constituição dirigente. Rio de Janeiro: Renovar, 2003.

DAVI, Kaline Ferreira. O direito administrativo, os atos de governo e os direitos sociais: uma análise a partir do neoconstitucionalismo. Revista do Programa de Pós-graduação da Universidade Federal da Bahia, Salvador, n. 13, p. 139-154, 2002.

DI PIETRO, Maria Sylvia Zanella. Direito administrativo. 15. ed. São Paulo: Atlas, 2003.

DI PIETRO, Maria Sylvia Zanella. Discricionariedade administrativa na constituição de 1988. 2. ed. São Paulo: Atlas, 2001.

DIAS, Jean Carlos. O controle judicial das políticas públicas. São Paulo: Método, 2007.

FAGUNDES, Miguel Seabra. O controle dos atos jurídicos pelo judiciário. 2. ed. Rio de Janeiro: J. Konfino, 1950.

FREITAS, Juarez. Discricionariedade administrativa e o direito fundamental à boa administração pública. São Paulo: Malheiros, 2007.

GARCÍA DE ENTERRÍA, Eduardo. La lucha contra las imunidades del poder en el derecho administrativo. Revista de Administracion Publica, Madrid, n. 38, p. 159205, maio/ago. 1962.

GARCÍA DE ENTERRÍA, Eduardo; FERNÁNDEZ, Tomás-Ramón. Curso de derecho administrativo. São Paulo: Revista dos Tribunais, 1990. v. 2.

GARCIA, Maria. Prefácio. In: BUCCI, Maria Paula Dallari (Org.). Direito administrativo e políticas públicas. 2. tir. São Paulo: Saraiva, 2006.

GORDILlO, Agostín. Tratado de derecho administrativo. 8. ed. Buenos Aires: Fundación de Derecho Administrativo, 2003. t. 1-2.

HESSE, Konrad. A força normativa da constituição. Tradução de Gilmar Ferreira Mendes. Porto Alegre: S. A. Fabris, 1991.

JUSTEN FILHO, Marçal. Conceito de interesse público e a personalização do Direito Adminsitrativo. Revista Trimestral de Direito Público, São Paulo, n. 26, p. 115-136, 1999. 
JUSTEN FILHO, Marçal. Curso de direito administrativo. São Paulo: Saraiva, 2005.

JUSTEN FILHO, Marçal. O Direito administrativo reescrito: problemas do passado e temais atuais. Revista Negócios Públicos, Curitiba, ano 2, n. 6, p. 39-41, 2005.

MEDAUAR, Odete. Direito administrativo moderno. 10. ed. São Paulo: Revista dos Tribunais, 2006.

MEIRELLES, Hely Lopes. Direito administrativo brasileiro. 33. ed. São Paulo: Malheiros, 2007.

MELLO, Celso Antônio Bandeira de (Org.). Estudos em homenagem a Geraldo de Ataliba. São Paulo: Malheiros, 1997.

MELlO, Celso Antônio Bandeira de. Curso de Direito administrativo. 20. ed. São Paulo: Malheiros, 2005.

MELLO, Celso Antônio Bandeira de. Discricionariedade e controle jurisdicional. 2. ed. São Paulo: Malheiros, 2003.

MODESTO, Paulo. Participação popular na administração pública: mecanismos de controle. Jus navigandi. Teresina, 2007. Disponível em: <http://jus2.uol.com.br/ doutrina/texto.asp?id=2586> Acesso em: 21 out. 2007.

MOREIRA NETO, Diogo de Figueiredo. Mutações do direito público. Rio de Janeiro: Renovar, 2006.

OTERO, Paulo. Legalidade e administração pública: o sentido da vinculação Administrativa a Juridicidade. Coimbra: Almedina, 2007.

PEREIRA, Luiz C. Bresser. Da administração burocrática à administração gerencial. Revista do Serviço Público, Brasília, ano 47, v. 120, n. 1, p. 95-105, jan./abr. 1996.

PEREZ, Marcos Augusto. A participação da sociedade na formulação, decisão e execução das políticas públicas. In: BUCCI, Maria Paula Dallari (Org.). Políticas públicas: reflexões sobre o conceito jurídico. São Paulo: Saraiva, 2006.

RIVERO, Jean. Direito administrativo. Coimbra: Almedina, 1981.

ROCHA, Cármen Lúcia Antunes. Princípios constitucionais da administração pública. Belo Horizonte: Del Rey, 2004. 
RUA, Maria das Graças. Desafios da administração pública brasileira: governança, autonomia, neutralidade. Revista do Serviço Público, Brasília, ano 48, n. 3, p. 133152, set./dez. 1997.

SARLET, Ingo Wolfgang. A eficácia dos direitos fundamentais. Porto Alegre: Livraria do Advogado, 2005.

SCHIER, Paulo Ricardo. Ensaio sobre a supremacia do interesse público sobre o privado e o regime jurídico dos Direitos Fundamentais. In: SARMENTO, Daniel (Org.). Interesses públicos versus interesses privados: desconstruindo o princípio da supremacia do interesse público. Rio de Janeiro: Lúmen Júris, 2005.

SCHIER, Paulo Ricardo. Filtragem constitucional. Porto Alegre: S. A. Fabris, 1999.

SOUSA, António Francisco de. A estrutura jurídica das normas de planificação administrativa. Lisboa: Danúbio, 1987.

SOUSA, António Francisco de. Conceitos indeterminados no direito administrativo. Coimbra: Almedina, 1994.

SOUZA, Wilson Alves de. Acesso à justiça e responsabilidade civil do estado por sua denegação: estudo comparativo entre o direito brasileiro e o direito português. 2006. 423 f. Tese (Pós-Doutoramento em Direito Público)- Universidade de Coimbra, Coimbra, 2006.

TÁCITO, Caio. A constituição e o direito administrativo. In: CORRÊA, Sérgio Moura (Org.). Temas de direito administrativo. Rio de Janeiro: Forense, 2006.

TÁCITO, Caio. Desvio de poder no controle dos atos administrativos, legislativos e jurisdicionais. Revista Trimestral de Direito Público, São Paulo, n. 4, p. 25-42, 1993.

WEBER, Max. Ciência e política: duas vocações. São Paulo: M. Claret, 2006.

ZANELLA, Maria Sylvia. Discricionariedade administrativa na constituição de 1988. 2. ed. São Paulo: Atlas, 2001. 
